\title{
LMS Solution: Evidence of Google Classroom Usage in Higher Education
}

\author{
Lejla Abazi-Bexheti, Arbana Kadriu, Marika Apostolova-Trpkovska \\ South East European University, Tetovo, Macedonia \\ Edmond Jajaga \\ University for Business and Technology, Pristina, Kosovo \\ Hyrije Abazi-Alili \\ Affiliate Fellow at CERGE-El, Prague, Czech Republic
}

\section{Abstract}

Background: Learning Management Systems (LMS) represent one of the main technology to support learning in HE institutions. However, every educational institution differs in its experience with the usage of these systems. South East European University's LMS experience is longer than a decade. From last year SEE University is adopting Google Classroom (GC) as an LMS solution. Objectives: Identifying factors which encourage LMS activities, with special emphasis on SEEU, might be of crucial importance for Higher Education academic leaders as well as software developers who design tools related to fostering LMS. Methods/Approach: This paper introduces new approach of investigating the usage of LMS, i.e. identifying the determinants of increasing usage of LMS activities, by conducting empirical analysis for the case of SEEU. We apply appropriate estimation technique such as OLS methodology. Results: Using SEEU Usage Google Classroom Report \& Analysis Data for spring semester (2016-2017) and winter semester (2017-2018) SUGCR dataset 2017, we argue that (i) LMS activities are affected by demographic characteristics and (ii) the students' LMS usage is affected by level and resources of instructors' LMS usage. Conclusions: The empirical results show positive relationship between student and instructors' LMS usage.

Keywords: e-learning, LMS, learning content, HE, Google Classroom, LMS usage JEL classification: O30, D83, 121

Paper type: Research article, Case Study

Received: Dec 01, 2017

Accepted: Mar 07, 2018

Citation: Abazi-Bexheti, L., Kadriu, A., Apostolova-Trpkovska, M., Jajaga, E., Abazi-Hilli, H. (2018), "LMS Solution: Evidence of Google Classroom Usage in Higher Education", Business Systems Research, Vol. 9, No. 1, pp. 31-43.

DOI: 10.2478/bsrj-2018-0003

\section{Introduction}

The most important issue about e-Learning is the technology that makes it possible. The major aim of this research is about the effectual application of that technology. In this direction, LMS maybe are not the latest innovative technology in recent years, but they are one of the most pervasive in higher education. 
The traditional mode of education was shifted forward towards new approaches in teaching and learning with the application of e-learning tools. This shift was mainly carried out by the implementation of LMS (Bersin et al., 2009).

LMSs are web-based technologies that provide to the instructors and the students the possibility to share materials, submit assignments as well as connect and chat online (Lonn et al., 2009). In other words, an LMS provides an online folder for the course management, where the instructor can post the teaching materials and assignments whilst the students can access the learning content, submit the assignments as well as participate in any other online learning activities.

The primary aim of LMSs was support learning management and consequently mostly were promoted tools for learning content management, student schedule, and attendance grading and similar. Many research studies and reports from the early period of LMS use raise the importance of the management functions of an LMS (Woolley, 1994; Nicholson, 2007). The later research is more and more focused on the student perspective, practices and their evaluation of the efficiency of the LMS features (Dyson et al., 2003; Aberdeen Group, 2008).

LMS's value was significantly increased especially as e-Learning is becoming one of the main activities in higher education institutions and for many of them crucial element in their strategy. The existing LMS practices and their use present an important practice in terms of education and technology. These practices among others show that it is the LMS usage that enables the users to identify the opportunities off the system and to require more from the system and in this way they actually became the key drivers of the LMS further development. Evaluating and monitoring the usability of an e-learning system is an important task to ensure the efficacy of the system (Shehu et al., 2009; Orfanou et al., 2015).

As Learning Management Systems keep evolving and being more and more accepted, further study and analysis are required in order to support the users in identifying the most efficient paths in the usage of these system and enhancement of the HE educational process.

Hence, in this study, quantitative data gathered from the LMS usage at South East European University were analysed. The data were analysed with linear regression method to find the impact of independent variables on enhanced LMS usage and to determine whether certain elements have influence on usage behaviour. This ethod was also used in earlier studies (Abazi-Bexheti et al., 2010; Mohd Ayub et al., 2010; Pardamean et al., 2012).

\section{South East European University's LMS experience}

South East European University's LMS experience can be divided in three phases. First phase includes the initial LMS usage at SEEU (2006-2008). This period a commercial LMS with a very reach menu of learning and managing features was in use. The system was used for more than three years at SEEU and this period was very important since it enhanced the e-learning culture among staff and students and helped us gather lot of data regarding the users' preferences on LMS (Abazi-Bexheti et al., 2009). Even though the system was very well excepted and used by the instructors and the students, due to its commercial model it was not possible to upgrade, extend or integrate with other University systems. Also because of the high costs, it was decided to switch towards in-house solution.

The main idea behind the in-house solution was to design and develop a system that could be integrated easily with other existing SEEU systems. The main advantage of the system would be that it could be enhanced based on user preferences and at the same time it could be integrated with other university systems such as roster, 
grading and similar. Therefore, in the second phase an in-house solution (Libri) was designed, developed and integrated with other existing University e-systems (AbaziBexheti et al., 2008). This phase lasted from 2008-2016. The initial version of Libri consisted of the tools that staff and students found as most important for their teaching and learning experience in the first phase (Abazi-Bexheti et al., 2009).

This is in fact one of the main reasons for the in-house approach: to design a LMS that would be in step with the up-to-date technologies and further on to explore, analyse and enhance it, based on users' experiences (Shehu et al., 2009).

The third phase of the LMS experience at SEEU started by the end of 2016, when on one side the LMS storage expenses started to increase and on the other side the in-house advancement and development of the system could not reach the pace of tools and developments that are coming from manufacturers and huge companies offered for free. The first advancement was done by integrating Libri with Google Drive. The purpose for this change was the issue that SEEU was dealing with the lack of storage for the learning contents. When it comes to storing data, cloud storage, more precisely Google Drive file repository system, was quickly seen as one of the best possible solution.

Google Classroom - LMS solution is in use at SEEU from sept 2016 to present, as a solution for the financial barriers and user' requirements in the past decade. In addition to this, the developed tool at SEEU, tracks the activity of the instructors in the system and on the system usage. Moreover, it generates reports which are further on analysed to identify the factors that maximize its usage.

\section{Assessment of a LMS usage}

Another perspective which raises considerable attention in HE institutions is how to be able to evaluate the actual level of LMS usage by the teaching staff. Actually, although the students are seen as the main drivers of the further system development, still the research shows that the teachers are the main drivers of the system usage (Alshamari, 2015). Hence, it's normal the focus of HE institutions on evaluation of the LMS usage by the teaching staff. The evaluation of the extend of LMS usage is complex process and in this direction, there are many research papers that study and analyse variety of aspects of LMS usage and employment (McQuiggan, 2007). The assessment method that we used is built upon the metric model for LMS evaluation proposed by Janossy, in which different value (level) is assigned for each certain group of activities on a LMS (Janossy, 2008). The metric model is simplified in four basic levels of usage based on the history of LMS usage data that we had at SEEU. The metric level model uses a different value for each certain group of activities on a LMS. In the proposed model:

Level 0 , is the null situation of LMS use. This level actually is the level of non-use of the system. It is the situation when the teaching staff does not post learning content on the system and the doesn't invite the students to enrol on the course, unless the course is created automatically for the students based on their schedule.

Level 1, is identified if the teacher is using the system for basic activities in terms of uploading Syllabi, lesson contents and assignments. At this level, students use the system for downloading learning materials and submitting assignments.

Level 2, includes the elements from the previous level and in addition to this the use of communication and assessment tools is identified. This level of LMS usage includes the usage of features such as quizzes, testes, surveys and similar by both teachers and students in this level. 
Level 3, covers more advanced use of the LMS which includes recording lessons and applying more innovative methodologies in course delivery such as flipping classroom

\section{Research objectives}

SEEU Usage Google Classroom Report \& Analysis Data has been developed as a tool for two purposes: (i) to track the activity of the instructors in the system and (ii) to analyse the factors that maximize its usage. The data generated from this tool, SUGCR dataset 2017, will be employed to empirically investigate the issue of the level of LMS usage, in order to identify the factors that enhance the LMS (GC) usage. Hence, Table 1 presents the identified factors employed in the model as determinants affecting level of LMS engagement.

Table 1

Description of the identified factors employed in the model

\begin{tabular}{ll}
\hline \multicolumn{1}{c}{ List of Variables } & \multicolumn{1}{c}{ Definition of the Variable } \\
\hline Students & Number of students enrolled \\
Level & Level 0, 1 and 2 \\
Resources & Number of resources published \\
Title & Academic title of the teaching staff \\
Age & Instructors' Age \\
Age square & Square of Age variable \\
Ethnicity & Instructors' ethnicity \\
Gender & Instructors' Gender \\
Semester & Dummy = 1 if Summer semester and O otherwise. \\
Students' Semester & Semesters 1-9 \\
\hline Source: Authors' work &
\end{tabular}

\section{Methodology}

The methodology section consists of two parts: (i) system design and implementation - presents the developed tool and its possibilities; and (ii) identifying factors that enhance LMS (GC) usage.

\section{System Design and Implementation}

The conceptual design of the proposed approach includes three main modules:

- dashboard, which displays individual instructors' course records

- reporting and analysis module, which is used to generate real-time and accurate reports about the activities within courses, and

- management module, which allows privileged system users to manage courses, course users' delegation and system users.

The solution was implemented as ASP.NET MVC application using Entity Framework (version 6) for dynamic management of database design and Google Classroom API for .NET for Classroom courses management. To have a single point of interaction between our server and Google servers, the Google OAuth 2.0 service account scenario was approached. Namely, a G Suite domain administrator account was used to access user data on behalf of users in the SEEU Classroom domain.

In UI perspective, the application was designated to include a page for the user's Dashboard (Figure 1), Reporting \& Analysis (Figure 2) and Course Management (Figure 3). The system can also provide data for reports such as the one shown in Figure la. In this report can be compared the start of uploading contents by the 
instructors between the initial summer semester and the second semester of the LMS (GC) usage.

Figure 1

The Application's UI Pages for an Administrator Account: Dashboard

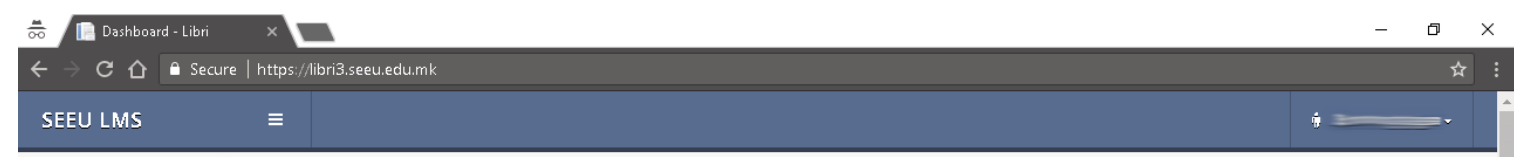

* Home ? Dashboard

Dashboard
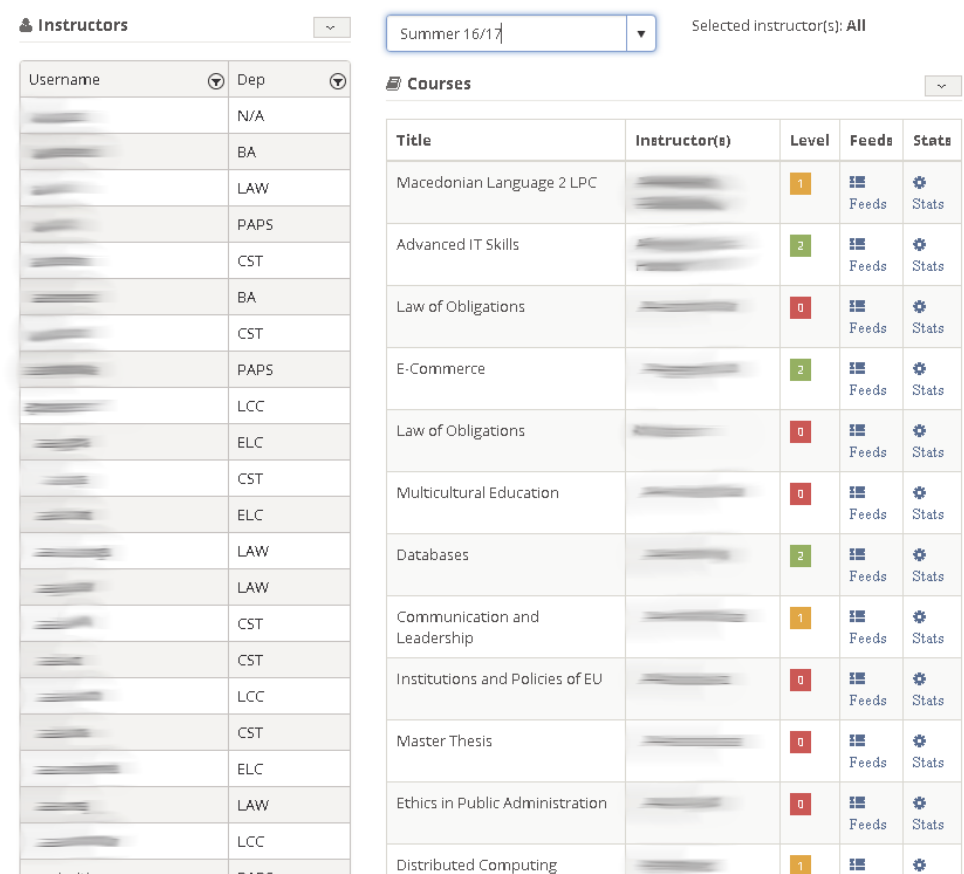

Soutput

Source: Authors' work

Figure 1.a

Number of courses started to publish content

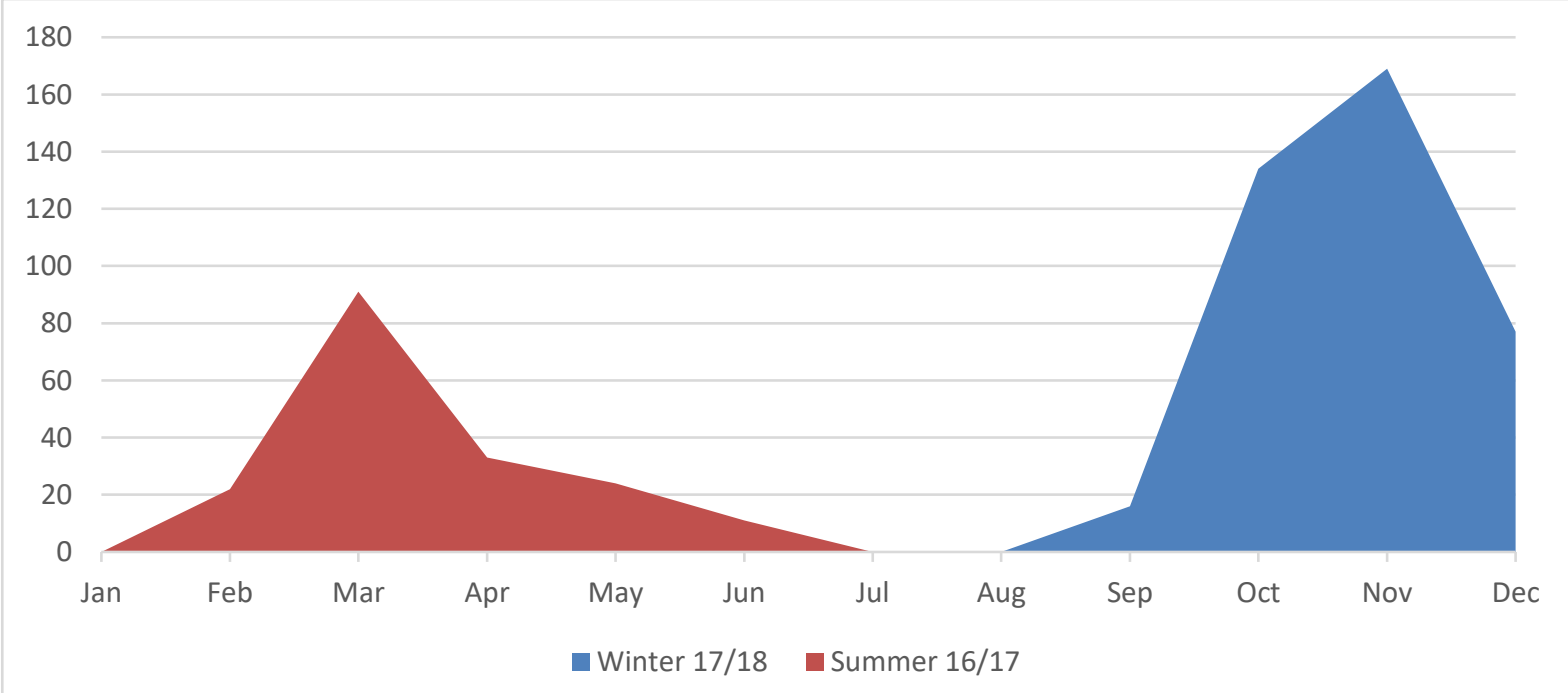

Source: Authors' work 
Figure 2

The Application's UI Pages for an Administrator Account: Reporting \&Analysis

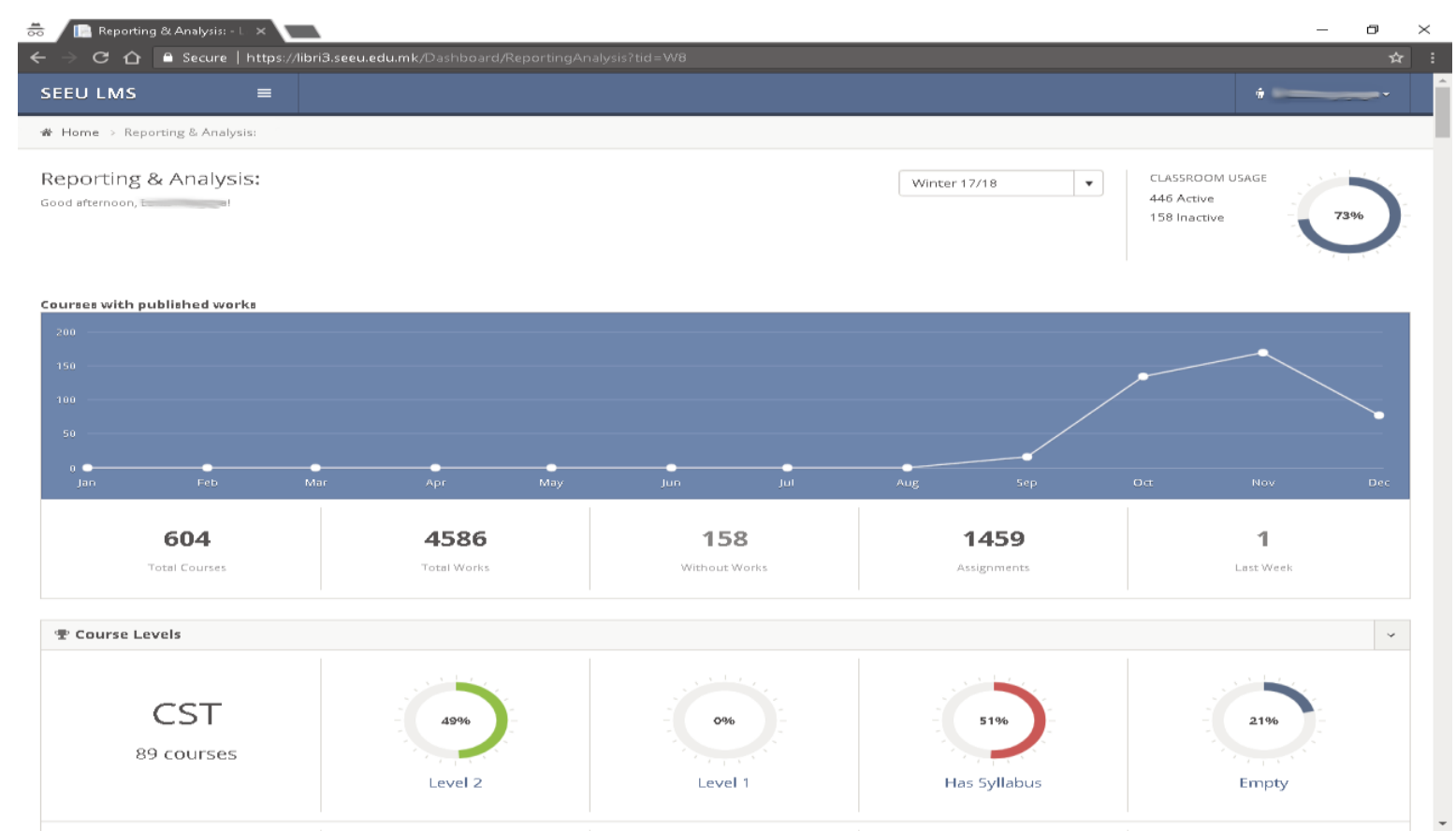

Source: Authors' work

Figure 3

The Application's UI Pages for an Administrator Account: Course Management

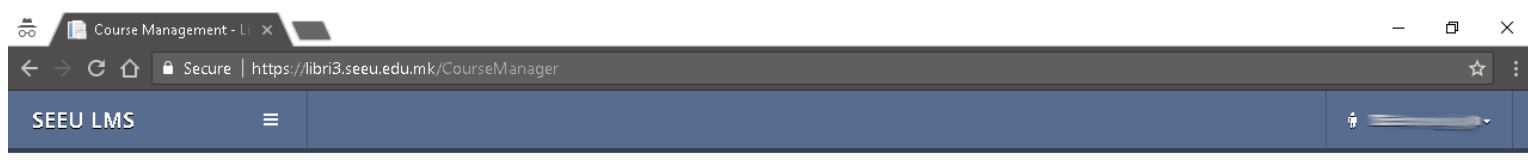

* Manage > Courses

Course Management

\section{Add New $\quad$ Add Multiple Courses}

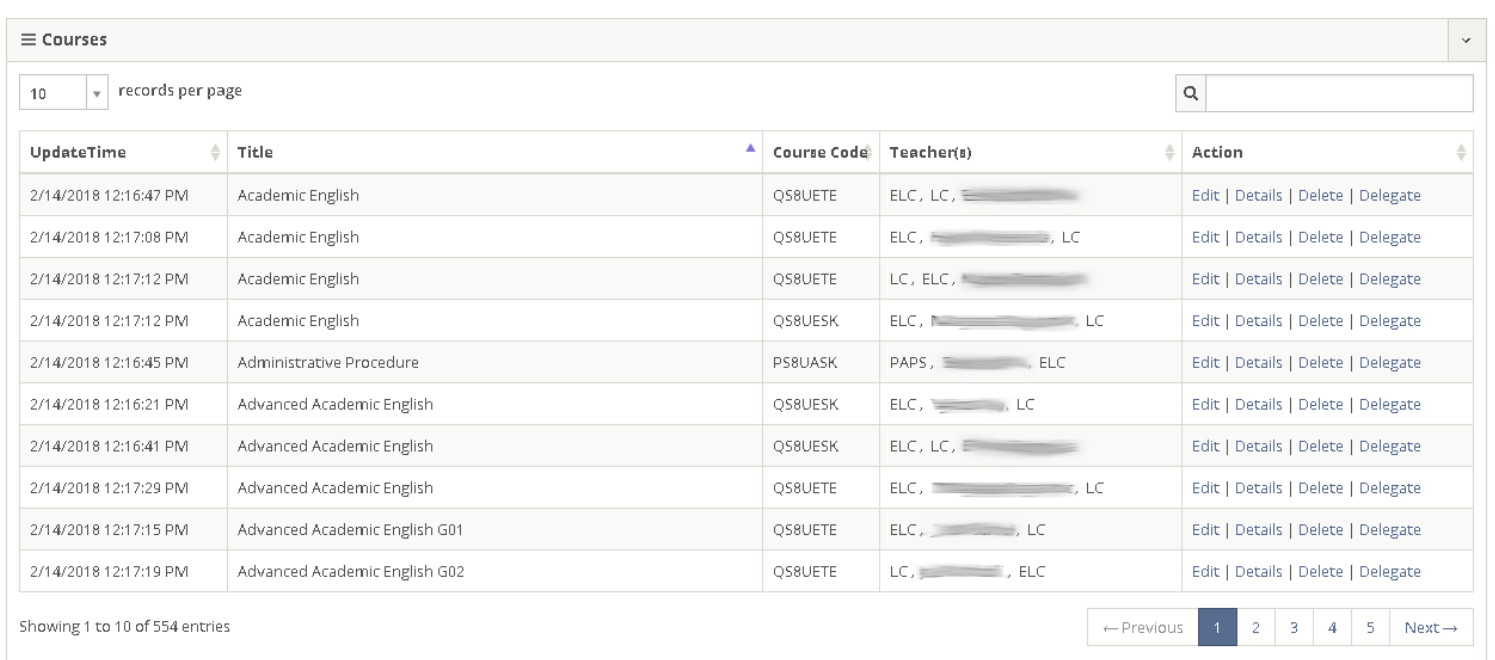

Source: Authors' work 
The system is used by three kinds of users: administrators, university academic leaders and faculty deans or directors of specific departments. Based on user role, the:

Dashboard page is divided into three columns, where the first one lists the instructor names, the second one the course list and the third one the course works (feeds) list or course stats. On first page load the three columns are populated based on specific user e.g. if the logged user is a dean of a faculty he/she will see the list of the instructor names on the first column, the list of the registered courses of the faculty on the second column and the list of published feeds of the faculty courses. After loading the initial lists, whenever a user clicks on an instructor name the course lists becomes populated with his/her courses and the course works lists includes the instructor's works across all course engagements. Moreover, if one wants to see the instructor's work on a specific course, he/she may click on the course name and the feeds list will become updated with only the records published within that particular course. Moreover, a link is provided for each course which displays the most current statistics of the selected course on the third column.

Reporting \& Analysis page consists of a set of reporting diagrams that enables deeper insight of course works for high management, deans and directors. Moreover, these users can observe course activities in near real-time. In the previous version of our system user requests were performed directly through Classroom API to consume real-time data. Because of the quotas for Google Services and for improving system performance, it was decided to build a local database with "offline" data i.e. data with maximum one-day delay. The synchronization algorithms run every night to update implicit and explicit course information. Moreover, a grid view of course level statistics within every department is also displayed for admins and university's high management, while deans and directors see only their department related information.

\section{Identifying factors that enhance LMS usage}

since there are few studies investigating empirically the usage of LMS, this exploratory paper uses research questions (rather than hypotheses) to examine LMS Usage and its determinants:

- RQ1: What are the determinants that influence the decision of students' enrolment in LMS (GC) at SEEU?

- RQ2: How can these determinants be reflected in enhanced usage of LMS (GC) by both students and instructors?

The effects of the identified factors employed in the previous research (AbaziBexheti et al., 2009), of LMS level of usage will be estimated using data generated from the tool, i.e. SUGCR dataset 2017. The data consists of 1011 observations, which at the same time presents the number of courses created on the GC. Out of these data, 74 courses that where 'tutoring' with no learning contents were deleted from the sample, thus the final sample consist of 937 courses.

The empirical methodology involves Ordinary Least Square (OLS) Regression model, where $Y_{i}$ is an unobserved continuous variable, described as dependent variable, and $X i$ are described as the explanatory variables (Menard, 2009):

$$
Y_{i}=\beta_{0}+\beta_{i} X_{i}+u
$$

In the context of this research $Y_{i}$ is the dependent defined by the enrolled students in GC, whereas $X_{i}$ are the explanatory variables presented at Table 1. The program 
used for the estimation is STATA 11 and the respective command for the estimation of this model is reg.

The unobserved continuous variable used in the model is enrolled students in GC, which takes values of minimum 0 , and maximum 30 students. Whereas the independent variables are resources, instructors' age, level of LMS usage, ethnicity, academic staff title, students' semester and gender. The summary statistics of the variables employed are presented in Table $2 a$ and $2 b$.

This research employs the OLS model to investigate the usage of LMS (GC) at SEEU, using SUGCR data 2017, by identifying the categorical variables in the model. The results provide evidence on the LMS (GC) learning activities and estimates their joint impact on GC usage.

Table $2 a$

Description of the Variables

\begin{tabular}{llllll}
\hline Variable name & Observations & Mean & $\begin{array}{l}\text { Standard } \\
\text { Deviation }\end{array}$ & Minimum & Maximum \\
\hline Students & 937 & 13.99 & 10.78 & 0 & 30 \\
Resources & 937 & 7.12 & 9.71 & 0 & 70 \\
\hline Instructors' Age & 937 & 45.09 & 8.98 & 25 & 68 \\
\hline Age square & 937 & 2114.57 & 861.97 & 625 & 4624 \\
\hline Students' semester & 937 & 3.88 & 2.25 & 1 & 9 \\
\hline
\end{tabular}

Source: Authors' work

Table $2 b$

Descriptive statistics of dichotomous variables

\begin{tabular}{llll}
\hline Variables & Obs. & Categories & $\%$ \\
\hline Gender & 937 & Male & 64.03 \\
Semester & & Female & 35.97 \\
& 937 & Winter & 59.02 \\
Level & & Summer & 40.98 \\
& 937 & Level 0 & 36.50 \\
& & Level 1 & 40.45 \\
Ethnicity & 937 & Level 2 & 23.05 \\
& & Albanian & 81.00 \\
Title & & Macedonian & 149 \\
& 937 & Foreign & 3.09 \\
& & Part-time Lecturers & 18.36 \\
& & Lector & 0.85 \\
& & PhD Assistant & 5.55 \\
& & High Lector & 15.37 \\
& & Docent & 13.34 \\
& & Associate Professor & 27.21 \\
\hline
\end{tabular}

Source: Authors' work

\section{Results}

The results of the OLS regression estimations are presented in the following Table (Table 3). The results presented include regression coefficient estimations of the the independent variables employed in the model. The variables level, ethnicity, title and students' semester are treated as categorical variables. 
Table 3

The Results of the Ordinary Least Square Regression

Independent Variables

OLS regression model

Dependent Variable: Number of students enrolled in google classroom

\begin{tabular}{|c|c|c|c|}
\hline & Coefficient & Std. Err & $P>|t|$ \\
\hline Resources & $0.265^{* * *}$ & (0.039) & 0.000 \\
\hline Age & $0.201^{*}$ & (0.328) & 0.054 \\
\hline Age square & $-0.003^{* *}$ & (0.003) & 0.042 \\
\hline \multicolumn{4}{|l|}{ Level } \\
\hline Level 1 & $6.573^{* * *}$ & (0.762) & 0.000 \\
\hline Level 2 & $6.779 * * *$ & (0.921) & 0.000 \\
\hline \multicolumn{4}{|l|}{ Ethnicity } \\
\hline Macedonian & $-2.273^{* * *}$ & (0.871) & 0.009 \\
\hline Foreign & $-3.559 * *$ & (1.587) & 0.025 \\
\hline \multicolumn{4}{|l|}{ Title } \\
\hline Lector & $5.473^{* *}$ & (2.889) & 0.059 \\
\hline PhD Assistant & 2.117 & (1.447) & 0.144 \\
\hline High Lector & $3.287^{* * *}$ & (1.082) & 0.002 \\
\hline Docent & 0.372 & $(1.096)$ & 0.734 \\
\hline Associate Professor & $2.425^{* *}$ & $(.996)$ & 0.015 \\
\hline Full Professor & 0.392 & $(1.085)$ & 0.718 \\
\hline Students' Semester & $-0.555^{* * *}$ & $(0.136)$ & 0.000 \\
\hline Gender & $-1.948 * * *$ & (0.7333) & 0.008 \\
\hline cons & 11.212 & (7.903) & 0.156 \\
\hline Observations & & 937 & \\
\hline$F(9,1001)$ & & 30.85 & \\
\hline Prob $>F$ & & 0.000 & \\
\hline R squared & & $30.33 \%$ & \\
\hline
\end{tabular}

The regression results can be reflected in the model as follows:

$$
\begin{aligned}
\text { students }=- & 2.271+0.265 \text { Resources }+0.201 \text { Age }-0.003 \text { Agesq }+6.673 \text { level } 1 \\
& +6.779 \text { level }-2.273 \text { Macedonian }-3.559 \text { Foreign }+5.473 \text { Lector } \\
& +2.117 \text { PhD Assistant }+3.287 \text { High Lector }+0.372 \text { Docent } \\
& +2.425 \text { Associate Professor }+0.392 \text { Full Professor }-0.555 \text { Semester } \\
& -1.948 \text { Gender }
\end{aligned}
$$

\section{Discussion}

After generating the OLS regression model for number of students the interpretation of the statistically significant variables, such as resources, age, age square, level, ethnicity, title, students' semester and gender, is as follows.

The coefficient of the variable resources is positive and statistically significant at $1 \%$ level of significance suggesting that instructors who are more active users of LMS, i.e. post more often learning content, seem to have higher student enrolment.

The relationship of the variables student enrolment and instructors' age is found to be statistically significant at $10 \%$ level of significance with non-linear i.e. inverse $U$ shaped relationship, as suggested by positive coefficient of age variable and 
negative coefficient of the age variable squared. In particular, student enrolment initially rises with instructors' age and reaches a maximum at the age of 39 (the turning point is calculated using the approach of Wooldridge (2002). In the estimated equation with $B>0$ (age in our case) and $B_{2}<0$ (age squared), the turning point is calculated as follows: $X^{*}=\left|B_{1} /\left(2 B_{2}\right)\right|=|0.201 /(2 * 0.0026)|=39$. Amongst the instructors who are aged more than thirty nine, the age effect is negative. The findings are reliable with our expectations of having younger generations of instructors being more IT literate. Even though age is found to be proxy of IT literacy, the findings of different studies diverge from positive result (Coşkunçay et al., 2013), through insignificant findings (Alghamdi et al., 2016), to those that found negative effect of age on LMS usage (Morris et al., 2000). Their findings indicate that with age the self-confidence of the technology usage is decreasing.

The coefficients of level 1 and level 2 are positive and significant. This indicates that instructors' enhanced usage of LMS (GC) increases the student enrolment.

The coefficients of different faculty titles are statistically significant. The base category is Part-Time engagement. As the positive and significant coefficients of lector, high lector, and associate professor suggest, given title of full-time engaged staff brings to better student enrolment.

The coefficient of the variable students' semester is negative and significant, thus suggests that earlier semesters tend to have higher enrolment of students in GC rather than the later ones.

The results show negative and statistically significant coefficient for gender. This means that the usage of GC i.e. number of students enrolled is better for female than for male. Study by Wichadee (2015), found no difference among instructors' gender differences in their attitude toward LMS, no matter what subject they were teaching. The following section provides the concluding remarks of the paper.

\section{Conclusion}

E-learning is equally treated as reason and outcome of important changes in the nature of the education concept, as well as changes in the understanding of how it should be successfully established. With the e-learning arrival and progress, SEEU started to deal with diverse activities to address emerging challenges that go beyond educational issues. The new advanced LMS solution included all the elements in respect to learning, teaching, communication, creation and management. It was a planned process that required digital skills, competences and techniques of designing the course and course instruction, communication methods through electronic and other technologies, along with crucial organizational and administrative procedures.

In this paper was introduced a new approach of investigating the usage of GC (LMS), i.e. identifying the determinants of the usage of GC activities, by conducting empirical analysis for the case of SEEU.

Using OLS Regression model we found that: (i) the level of usage GC has positive impact on the number of students enrolled; (ii) the resources posted by the academic staff also confirm the appropriateness of the usage of GC, where without significant number of resources there is no increase in the student enrolment; (iii) there is an inverse U-shaped relationship between age and the usage of LMS reaching a maximum at the age of 39 , which is in accordance with our expectations due to the IT literacy needed for the use of technologies. Older members of the academic staff have lower level in IT literacy; (iv) females are more prone to the LMS usage. Thus, in order to enhance LMS usage by students, instructors should consider adding additional resources and increase their Level of LMS usage. 
This study limitation is the time span of the data. These data reflect two semester observation and usage which is limited time period. Once the data for the next academic year will be generated, one can consider trend and suggestions for further developments.

\section{References}

1. Abazi-Bexheti, L., Dika, Z., Alili, H. (2009), "Analysis Report of Survey Results About The Usage Of A Learning Management System", International Conference on e-Education and elearning, Vol. 54, World Academy of Science, Engineering and Technology, Paris, pp. 225-229.

2. Abazi-Bexheti, L., Dika, Z., Besimi, A. (2008), "In house Development of Learning Managment Systems Using Modular Approach", Proceedings of Ed-Media World Conference on Educational Multimedia, Hypermedia \& Telecommunications, Association for the Advancement of Computing in Education, Vienna, pp. 5915-5920.

3. Abazi-Bexheti, L., Kadriu, A., Ahmedi, L. (2010), "Measurement and Assessment of Learning Management System Usage", 6th WSEAS/IASME International Conference on educational technologies (EDUTE '10), Kantaoui, Sousse, Tunisia, pp. 183-186.

4. Aberdeen Group (2008). Research brief: The rice of Learning Management Systems in Talent Management Systems, Abeerden, Boston.

5. Alghamdi, S. R., Bayaga, A. (2016), "Use and attitude towards Learning Management Systems (LMS) in Saudi Arabian universities", Eurasia Journal of Mathematics, Science \& Technology Education, Vol. 12, No. 9, pp. 2309-2330.

6. Alshammari, M. S. (2015), „Academics' Adoption and Usage of Learning Management Systems", available https://www.dora.dmu.ac.uk/bitstream/handle/2086/1 1 123/Thesis_Mohammed\%20S.\%20 Alshammari_26May2015.pdf (30 March 2017)

7. Bersin, J., Howard, C., O' Leonard, K., Mallon, D. (2009). Learning Management Systems2009: Facts, Practice Analysis, Trends and Provider Profiles, Bersin \& Associates.

8. Coşkunçay, D. F., Özkan, S. (2013), "A Model for Instructors' Adoption of Learning Management Systems: Empirical Validation in Higher Education Context", Turkish Online Journal of Educational Technology, Vol. 12, No. 2, pp. 13-25.

9. Dyson, M. C., Baretto Campello, S. (2003), "Evaluating Virtual Learning Environments: what are we measuring?", Electronic Journal of e-Learning, Vol. 1, No. 1, pp. 11-20.

10. Janossy, J. (2008), "Proposed Model for Evaluating C/LMS Faculty Usage in Higher Education Institutions", Immersed In Learning, 13th Annual Instructional Technology Conference, Middle Tennessee State University, Murfreesboro.

11. Lonn, S., Teasley, S. D. (2009), "Saving time or innovating practice: Investigating perceptions and uses of Learning Management Systems", Computers \& Education, Vol. 53, No. 3, pp. 686-694.

12. McQuiggan, C. A. (2007), "The role of faculty development in online teaching's potential to question teaching beliefs and assumptions", Online Journal of Distance Learning Administration, Vol. 10, No. 3.

13. Menard, S. (2009). Logistic Regression: From Introductory to Advanced Concepts and Applications, SAGE Publications.

14. Mohd Ayub, A. F., Tarmizi, R. A., Wan J., Wan M., Wan A., Wan Z., Luan, W.S. (2010), "Factors Influencing Students' Use a Learning Management System Portal: Perspective from Higher Education Students", International Journal of Education and Information Technologies, Vol. 2, No. 4, pp. 101-108.

15. Morris, M. G., Venkatesh, V. (2000), "Age differences in technology adoption decisions: implications for a changing work force", Personnel Psychology, Vol. 53, No. 2, pp. 375-403.

16. Nicholson, P. (2007), "A history of E-learning", in Fernández-Manjón, B., Sánchez-Pérez, J. M., Gómez-Pulido, J. A., Vega-Rodríguez, M. A., Bravo-Rodríguez, J. (Eds), Computers and education, Springer, Dordrecht, pp. 1-11. 
17. Orfanou, K., Tselios, N., Katsanos, C. (2015), "Perceived usability evaluation of learning management systems: Empirical evaluation of the System Usability Scale", International Review of Research in Open and Distributed Learning, Vol. 16, No. 2, pp. 227-246.

18. Pardamean B., Susanto M. (2012), "Assessing User Acceptance toward Blog Technology Using the UTAUT Model", International Journal of Mathematics and Computers in Simulation, Vol. 6, No. 1, pp. 203-212.

19. Shehu, V., Besimi, A., Abazi-Bexheti, L., Shaqiri, M. (2009), "Usability Issues While Building A New LMS", Proceedings of the 31st International Conference on Information Technology Interfaces, SRCE, Cavtat, Croatia, pp. 317-322.

20. Wichadee, S. (2015), "Factors Related to Faculty Members' Attitude and Adoption of a Learning ManagementSystem", Turkish Online Journal of Educational Technology, Vol. 14, No. 4, pp. 53-61.

21. Woolley, D. R. (1994), "PLATO: The Emergence of Online Community", available at http://www.thinkofit.com/plato/dwplato.htm (15 December 2008) 


\section{About the authors}

Lejla Abazi-Bexheti is Associate Professor at the Faculty of Contemporary Sciences and Technologies at South East European University in Macedonia. She holds a PhD Degree in Computer Science and has been part of the CST teaching staff since 2002. Her main research activity is in the area of Learning Systems and eLearning and she has been involved in many international projects and research activities from this area. At SEE University she was involved on resolving issue of the Learning Management System. Currently she is Pro-rector for academic issues at SEEU. The author can be contacted at l.abazi@seeu.edu.mk

Edmond Jajaga is an assistant professor at the Department of Computer Engineering of the University of Business and Technology in Kosovo. He received his PhD in 2017 in Computer Science from South East European University, Macedonia. He has published in renowned international venues in the areas of Semantic Web, elearning, Stream Reasoning and Databases. He has been involved on a couple of international projects including InWaterSense and DISCO. Since 2011, he has been working as a software engineer at the eLearning Center of the South East European University. In the past he has worked as a teaching assistant at the State University of Tetova and University of Prishtina. The author can be contacted at edmond.jajaga@ubt-uni.net

Dr. Hyrije Abazi-Alili is a Lecturer Assistant of Economics, Quantitative Methods and Corporate Finance modules at the Faculty of Business and Economics at South East European University since 2005. She finished her PhD at Staffordshire University in 2013. She is affiliate fellow at CERGE-El, Prague since 2014. Her field of research is on microeconomics such as ownership change, innovation, entrepreneurship, education, gender issues, etc., in transition economies. She has participated in numerous international projects (EU projects, UNDP, RRPP, etc) as project manager, senior researcher, and other engagements. She is also active in publishing her academic research work. The author can be contacted at h.abazi@seeu.edu.mk

Arbana Kadriu holds a PhD degree in Computer Sciences from Ss. Cyril and Methodius University in Skopje from 2008, with focus on natural language processing and information retrieval. She is associate professor at the Faculty of Contemporary Sciences and Technologies at SEE University in Macedonia. She has also background in artificial intelligence, machine learning, programming paradigms, software engineering and e-learning. Also, she is mentoring several master theses that involve the web information retrieval and e-learning. She is author of more than 30 research papers. The author can be contacted at a.kadriu@seeu.edu.mk

Marika Apostolova-Trpkovska, Assist. Professor at the Faculty of Contemporary Sciences and Technologies, SEE University in Macedonia. She has been part of the CST teaching staff since 2006. During her teaching experience, she has taught courses from the area of Data structures and algorithms, C++ programming, Web programming, Software Engineering, Strategic Information Technology Project Management, Interactive system design and Microsoft IT courses. Her main PHD research activity was in the area of e-Medical services based on Semantic web and elearning. She acted as coordinator of DISCO - Erasmus+ international project, and senior researcher on several national and international projects. She was also coordinator of integrated study programmes that were part of a valuable project between German Federal Government of Development Cooperation and SEEU. The author can be contacted at m.apostolova@seeu.edu.mk 